\title{
The PIAAC Numeracy Framework: A Guide to Instruction
}

\author{
Donna Curry, Center for Adult Numeracy, TERC
}

Adult learners come to our classes at all different levels, with misconceptions, gaps in some areas but strengths in others. There is no class that is truly homogeneous, especially if the class is based on a one-time multiple-choice test. This messiness is one reason many adult education math teachers feel like the best way to work with their students is to have them all in separate workbooks (including "tech-based workbooks") which typically focus on decontextualized procedural practice - a unit each on fractions, decimals, data, geometry, etc. And, because this is the model that most practitioners are used to seeing, they simply follow the workbook (or virtual lessons). They often have trouble figuring out how to differentiate instruction other than to have every student on a different page in the workbook. This means that there is little classroom discussion about topics of significance to students and students rarely see math as useful in their lives. Their main purpose for learning math in the adult education classroom is often just to pass the "test."

The Program for International Assessment of Adult Competencies, better known as PIAAC, developed

\section{What is PIAAC?}

In 2013, the Organization for Economic Cooperation and Development (OECD) released the first results of a multi-cycle program of assessment of adult skills - the Program for International Assessment of Adult Competencies (PIAAC). Twenty-four countries-including the U.S. and most other developed countries in the world-participated in the first round of this assessment in 2011-12, which was designed to give countries critical information on how well-prepared their adult residents were to participate fully in the civic, cultural and economic life of their countries in the 21st century. In addition to assessing three key information-processing skills-literacy, numeracy, and problem solving in technology-rich environments-PIAAC included a skills use module, which collected information from each participant on additional skills used in the workplace, including communication, interpersonal, problem-solving and learning skills, as part of an extensive background questionnaire, which collected information on education and work history, in addition to demographic data, that would help each country understand the range and distribution of skills among its adult population so that it could use the assessment data to make important policy decisions about the best ways to improve adult skills. Taken together, these features of PIAAC make it the most comprehensive assessment of adult skills undertaken to date. 
a numeracy assessment framework that was used internationally to assess adults' numeracy skills. The assessment gauged adults' (aged 16 - 65 years) numeracy skills across a full range, from adults with very low levels of numeracy to college level math ability. PIAAC's assessment framework is based on two concepts: math as being use-oriented and math proficiency as a continuum. While this framework was designed to measure adults' numeracy ability in a structured assessment environment (including adults' home with trained evaluators), it is useful beyond its original intent. This framework can be used to help teachers better understand how to differentiate instruction while still focusing on a particular theme or topic in a classroom, ensuring rich discussions about topics of interests to students. This can be flexibly done once teachers become comfortable with the PIAAC numeracy framework.
In this article, we will discuss several key elements of the PIAAC assessment framework, including the definition of numeracy and numerate behavior, facets of numerate behavior, enabling processes that support such behavior, and complexity factors that determine the difficulty of the task requiring numerate behavior. Although we will discuss these in isolation, they are all integrated and interdependent. We will bring them all together to illustrate their interrelatedness near the end of this article. It is not necessary to remember what the various elements and factors are called. What is important is that teachers deepen their understanding of these various PIAAC numeracy components so that they can apply them by making tweaks to activities and tasks they assign their students. With a better understanding of the underpinnings of the PIAAC numeracy framework,

\section{Table 1: Parallel tasks at different levels}

TASK 1: Amy can only eat $10 \mathrm{~g}$. of sugar per day. If she eats one serving of this cereal, how many more grams of sugar can she have during the rest of the day?

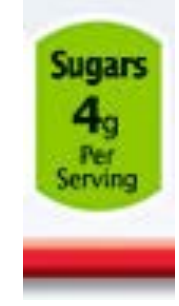

TASK 3: Amy's doctor has told her that she needs to reduce her calorie intake down to 1500 per day. If she eats a serving of this cereal, explain what percent of her daily calorie intake she has consumed.

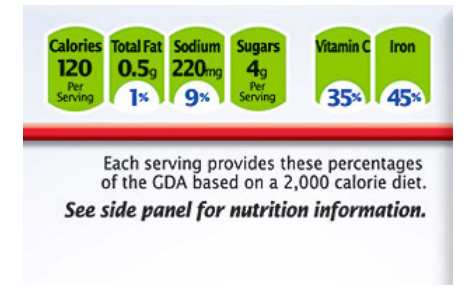

TASK 2: Compare the nutritional information of the cereal below with the cereal you usually buy. Create a chart showing how the two compare, then be prepared to explain which cereal is the healthier choice for your specific needs.

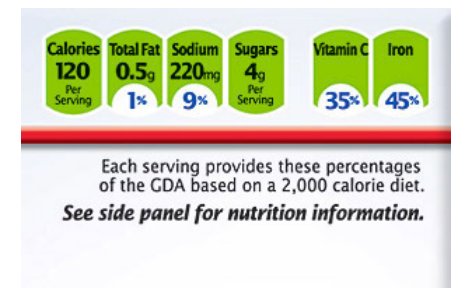

TASK 4: Amy can only eat $10 \mathrm{~g}$. of sugar per day. If she eats one serving of this cereal, how many more grams of sugar can she have during the rest of the day?

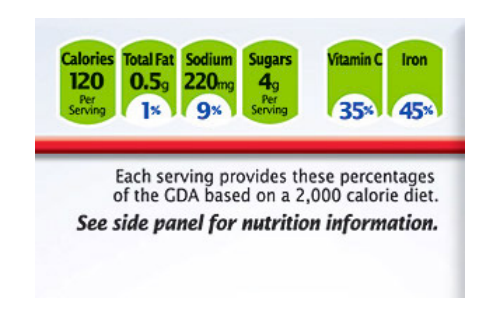


teachers can efficiently differentiate instruction by adjusting features of a numeracy task.

Let's look at a quick example to get started. Teachers can differentiate by providing tasks that are both use-oriented and appropriate for students at different levels of proficiency like the set of tasks below which involve nutrition, a topic that is relevant to adults' lives. Let's take a quick peek at what four similar tasks involving nutritional information could entail. (We will look at these four tasks in detail later in this article. As you read about PIAAC's framework, keep these tasks in the back of your mind.)

You can see that analyzing nutritional labels can seem like a fairly easy task or one that is quite involved. In this article we will look at the specific elements from the PIAAC Numeracy framework that teachers need to consider as they create tasks or activities to address the different needs of their learners. We will return to this set of examples later to see explicitly what elements are involved in making the task more or less complex.

\section{Numeracy and Numerate Behavior}

PIAAC defines numeracy as the ability to access, use, interpret, and communicate mathematical information and ideas, in order to engage in and manage the mathematical demands of a range of situations in adult life. In other words, adults are expected to do something with the mathematical information they interact with at ALL levels. We use math for a purpose (not just to pass the test).

We know that math has a purpose in our lives, way beyond passing a high-stakes assessment. Unfortunately, too often our students do not see the value of the math they are learning in class. Even when students know that they use math in their lives, they see the math taught is the classroom as just 'school math' - something that is done only in a math class for the purpose of taking a test. According to Givvin, Stigler, and Thompson (2011), "the intuitive concepts that supported their thinking and reasoning when they were younger began to atrophy, serving no purpose in the world of school mathematics" (p.5). Perhaps if teachers embraced PIAAC's definition of math/numeracy, they would be more explicit in creating tasks or activities that give students opportunities to apply the math they are learning.

Let's take a closer look at what it means to be use-oriented. Table 2 is a full description of what numerate behaviors involve, according to PIAAC.

The facets of numerate behavior listed above - contexts, responses, mathematical content/ information/ideas, and representations - were key to the development of the PIAAC assessment framework and the development of PIAAC assessment tasks. These four facets should be fundamental in guiding teachers in using (or creating) instructional activities that move students toward increased numerate behavior that they can apply in multiple contexts.

Let's look at each of these a little more closely.

Facet 1: Contexts. In our everyday life we encounter many numeracy tasks, some simple and some more complicated. The tasks may come from work, society and community, education and training, or from students' personal/family lives. An effective teacher is someone who can point to many instances of these tasks to show her students the prominence of numeracy tasks in everyday life-or to ask her students to point out numeracy tasks and their importance in their own lives. The teacher needs to be a good listener to tune in to contexts important in students' lives. This is critical since students' needs and concerns may be different from those of their teachers. For example, students may be struggling to cope from weekly paycheck to 


\section{Table 2: Numerate behavior - key facets and their components (from Conceptual Framework, p. 21)}

Numerate behavior involves managing a situation or solving a problem...

1. in a real context:

- everyday life

- work

- society

- further learning

2. by responding:

- identify, locate or access

- act upon and use: order, count, estimate, compute, measure, model

- interpret

- evaluate/analyze

- communicate

3. to mathematical content/information/ideas:

- quantity and number

- dimension and shape

- pattern, relationships, change

- data and chance
4. represented in multiple ways:

- objects and pictures

- numbers and mathematical symbols

- formulae

- diagrams and maps, graphs, tables

- texts

- technology-based displays

5. Numerate behavior is founded on the activation of several enabling factors and processes:

- mathematical knowledge and conceptual understanding

- adaptive reasoning and mathematical problemsolving skills

- literacy skills

- beliefs and attitudes

- numeracy-related practices and experience

- context/world knowledge weekly paycheck, or to cope with stressful family situations, or a history of incarceration.

In an adult education classroom, the contexts might overlap for students with different levels of skills. Health care, for example could be a context that applies to all levels of learners; it is part of adults' personal lives. If students are working or preparing for a particular kind of work - the context can readily come from situations that they could encounter on the job. These contexts should form the basis for rich discussions in the classroom that show the value of doing math.

Facet 2: Responses. The ways in which adults react to mathematical tasks or information are shaped by their purposes for using that information. PIAAC classified these purposes into three groups of cognitive strategies:
- those required to identify, locate, or access mathematical information;

- those required to act upon or use mathematical information; and

- those required to interpret, evaluate, analyze, or communicate mathematical information.

In almost any mathematical task, adults need to identify, locate, or access information in order to address the situation. This could be as simple as finding the price tag on a piece of clothing to determine its cost, or checking the estimated area that a can of paint will cover. However, locating information isn't always as easy as reading a label. Information can be more challenging to access or locate, such as scouring through a set of data to look for patterns or relationships or to determine what is needed to make a point. 
Often, the response of identifying, locating, or accessing information is performed in tandem with one of the other two sets of cognitive strategies, particularly when the purpose of the task is not simply finding or locating information. Once an adult has located information, he may use that information in different ways such as ordering, counting, estimating, computing, measuring, or modeling. For example, once someone finds the price tag on an article of clothing, he will need to decide whether the price is within his budget or may want to add that price to other items to estimate the total cost. Or, once an individual finds how much area a can of paint will cover, he will need to determine the area of the room to be painted and then will have to figure out just how many cans of paint he should buy. In fact, in order to determine the area to be painted, the individual might need to measure the room, then use a formula to determine the area of each wall.

The third group of responses involves interpreting, evaluating/analyzing, and communicating. This group of responses usually is used in connection with at least the first type of response - locate, identify, and access - since clearly an individual has to have information to interpret or communicate. The interpretation may include judging or giving opinions. For example, in a simpler task, an individual might need to locate the scale on a map, then estimate the length of time to get from one place to another. Tasks requiring the interpretation of data from graphs vary in difficulty depending on the type of graph (simple bar graph to very complex graphs illustrating lots of data) and question to be answered (such as how the categories compare vs. what patterns or trends the graph suggests). The response of evaluate and analyze requires interpretation but is based on some criteria or demands. A task requiring evaluation and analysis would be a high-level situation where an individual might review a huge set of data to determine whether the data are valid, or needed for the situation, or include gaps.

This third group of responses also includes communication. Communication could include a description of how one arrived at a conclusion, or a justification of the reasoning used in an analysis or interpretation. Communication can be oral or written; written communication can be through a drawing or graph or map, or even a computergenerated display such as a spreadsheet. A simple task might require someone to draw a picture to represent the total number of bottles stocked on a shelf. A higher-level task might require an individual to give an oral presentation justifying why one situation is better than another.

These three types of responses are usually used in various combinations, depending on the numeracy task at hand. Over time, the teacher needs to pay attention to the types of responses she is asking her students to provide so that they have practice not just with locating or acting upon mathematical information but also with evaluating the information and communicating about it.

\section{Facet 3: Mathematical Content/information/}

ideas. Mathematical information has been classified in different ways. The College and Career Readiness Standards for Adult Education (CCRS) use domains to describe mathematical content. The National Council of Teachers of Mathematics (NCTM) uses five strands: numbers and operations; functions, relations, and algebra; data; geometry; and measurement. In PIAAC, mathematical content and ideas are classified as quantity and number; dimension and shape; data and chance; and patterns, relationships and change. In the table below, you see how these different approaches align. 


\section{Table 3: Mathematical Content}

\section{MATHEMATICAL CONTENT/INFORMATION/IDEAS CLASSIFICATIONS}

\begin{tabular}{|c|c|c|}
\hline (NCTM) & (CCRS) (domains for $\mathrm{K}-8$ only) & PIAAC \\
\hline Numbers and operations & $\begin{array}{l}\text { Number and operations in base ten }(K-5) \\
\text { The number system }(6-8) \\
\text { Number and operations - fractions }(3-5) \\
\text { Ratios and proportional relationships }(6-7)\end{array}$ & Quantity and number \\
\hline Data & Statistics and probability (6 - 8) & Data and chance \\
\hline Measurement & Measurement and data $(\mathrm{K}-5)$ & \multirow[t]{2}{*}{ Dimensions and shape } \\
\hline Geometry & Geometry $(K-8)$ & \\
\hline $\begin{array}{l}\text { Functions, relations, and } \\
\text { algebra }\end{array}$ & $\begin{array}{l}\text { Operations and algebraic thinking }(\mathrm{K}-5) \\
\text { Expressions and equations }(6-8) \\
\text { Functions (8) }\end{array}$ & $\begin{array}{l}\text { Patterns, relationships } \\
\text { and change }\end{array}$ \\
\hline
\end{tabular}

Table 4 below further details the content specific to the PIAAC framework.

Table 4: Mathematical content/information/ideas (adapted from Conceptual Framework, pp. 27 - 28)

\begin{tabular}{l|l}
$\begin{array}{l}\text { MATHEMATICAL CONTENT/ } \\
\text { INFORMATION/IDEAS }\end{array}$ & \multicolumn{1}{c}{ DESCRIPTION } \\
\hline Quantity and number & $\begin{array}{l}\text { Quantity is using attributes that allow individuals } \\
\text { to quantify the world (such as cost, temperature, } \\
\text { growth rate). Number is fundamental to } \\
\text { quantification: whole numbers; fractions, } \\
\text { decimals, percents; positive and negative } \\
\text { numbers. In addition to quantification, numbers } \\
\text { are used to put things in order and as identifiers } \\
\text { (e.g., telephone numbers or zip codes). }\end{array}$ \\
\hline Dimension and shape & $\begin{array}{l}\text { Dimension includes 'big ideas' about what can } \\
\text { be measured in 1-, 2-, and 3-dimensional items, } \\
\text { including length, area, and volume. Shape } \\
\text { describes real 2- and 3- dimensional images } \\
\text { such as a house or sign. }\end{array}$ \\
\hline Pattern, relationships, & $\begin{array}{l}\text { Pattern relates to those patterns seen around } \\
\text { us (including in music, nature, etc.) Relationship } \\
\text { and change }\end{array}$ \\
and change refer to how things in the world are \\
related or develop.
\end{tabular}

Data and chance
Data involves ideas such as variability, sampling, data collection, etc. Chance relates to probability and relevant statistical methods.

\section{SAMPLE TYPES OF TASKS}

A numeracy task with less cognitive demand might be figuring out the cost of one can of soup, given the cost of 4 for $\$ 2.00$. A task with a higher cognitive demand could involve figuring out the cost when buying 0.28 pound of cheese at $\$ 4.95$ per pound.

A task with lower cognitive demand could be shape identification. A higher level could involve a description of the change in capacity of an object when one of its dimensions is changed.

A task with lower cognitive demand may ask someone to describe the simple pattern in how bottles are stocked on shelves. A task with a much higher cognitive demand might require the use of spreadsheets to compare rates.

A task with lower cognitive demand might be the interpretation of a simple pie chart. A task with a higher cognitive demand could involve determining the likelihood of an event occurring, based on past information. 
In the approach to these content areas, teachers need to be aware of how students might need to use this content. It's not enough to teach rote procedures in a particular content area; students need to know how they are going to use those procedures in order to accomplish a task. As noted above, at all levels of tasks, individuals are expected to interact with the content. At the most basic level a student learns about quantity and number so he can address a question or situation that has a mathematical component to it. It could be as simple as someone trying to figure out if he has enough money to buy several items. The situation requires the use of quantity and number - a clear purpose within a real-life situation.

\section{Facet 4: Representations of mathematical} information. Mathematical information can be represented in various formats. We often think of mathematical information being presented as numbers and symbols, including formulae. For example, the idea of five can be represented using the symbol 5, or the Roman numeral V or even four tick marks with a slash mark through them (H一). Information can be represented by simply using objects to be counted. A simple picture could also be used by an individual to count or address a question. Mathematical information can be represented using visual displays such as charts, graphs, tables, and maps, including technologybased displays. And mathematical information can be represented by text. For example, five is the text version that corresponds to 5 and $\mathrm{V}$.

It is important for teachers to be aware of different representations, so they make sure they include a variety of them as they work with students. They can differentiate tasks in their classroom by varying the type of representation required of students, or that students use in addressing a situation with a mathematical component. For example, teachers might present data in

\section{Table 5: Numerate behavior - key facets addressed in a simple task}

TASK: Survey the class on a question that you want to know more about, making sure to ask for yes/no responses only. Create a pie chart representation and explain using benchmark fractions and percents what the results were.

[Note: this is NOT the way this activity would be explained to adult learners. There would be modeling with paper plates for pie charts and lots of classroom lessons before assigning this or any of the other tasks described in this paper.]

CONTEXT
Surveys are often conducted
for work and community; this
activity models a very basic
survey format.

survey format.

\section{MATHEMATICAL CONTENT/} INFORMATION/ IDEAS

Students do not have to draw a pie graph; instead they use concrete models made from paper plates to estimate whether each set of responses is more or less than the benchmark $50 \%$; they orally present their results to the class using their benchmark descriptors along with the question and number of yes/ no responses.
Data collection and analysis are the main ideas, but benchmark fractions and percents are incorporated so students have examples of how they are used in life; having students create their own question and collect their own data gives them a better understanding of the basics of data collection and analysis.

\section{REPRESENTATION}

Students simply use tick marks to tally their responses. 
chart form or in a table where students have to extrapolate the necessary information in order to address a task. And, teachers might ask their students to represent the results of their task in a chart or graph or even an equation. Students need to be exposed to these various representations and explicitly taught how to identify and get to the math behind the real-world stimulus.

Table 5 (on page 41) illustrates how all four facts of numerate behavior can be addressed in a single task.

The following questions should guide the teacher as she considers how to integrate all four facets when designing activities/tasks for students to apply their learning.

\section{Enabling Processes}

Along with the four facets of numerate behavior, the PIAAC definition of numeracy includes several enabling processes that adults need to activate (and teachers need to help develop in their students) in order to engage in numerate behaviors. These enabling factors and processes influence the successful completion of numeracy tasks, and this is what starts to make teaching challenging and messy. Naturally some students are better able than others to activate these processes. These processes include context/ world knowledge, mathematical knowledge and conceptual understanding, adaptive reasoning and problem-solving skills, beliefs and attitudes,

\section{Table 6: Facets of numerate behavior - questions to consider}

\begin{tabular}{|c|c|}
\hline $\begin{array}{l}\text { FACETS OF NUMERATE } \\
\text { BEHAVIOR }\end{array}$ & QUESTIONS A TEACHER MIGHT ASK HERSELF \\
\hline Context & $\begin{array}{l}\text { Is the context meaningful for students? } \\
\text { Are students familiar with the context? } \\
\text { Can the actual context be transformed into a more familiar context if working at lower levels? }\end{array}$ \\
\hline Responses & $\begin{array}{l}\text { What are students going to do with the mathematical information? } \\
\text { What actions do they need to undertake? } \\
\text { What strategies will they use? } \\
\text { What cognitive process(es) is/are required to address the situation? } \\
\text { Is there an opportunity to ask students to communicate something about the information? }\end{array}$ \\
\hline $\begin{array}{l}\text { Mathematical content/ } \\
\text { information/ ideas }\end{array}$ & $\begin{array}{l}\text { What is the math that students are learning? } \\
\text { What do students already know? } \\
\text { How have students shown what they know and understand? } \\
\text { How can students show that they can apply the math that they are learning? }\end{array}$ \\
\hline $\begin{array}{l}\text { Representations of } \\
\text { mathematical information }\end{array}$ & $\begin{array}{l}\text { In what format (chart, graph, picture, etc.) is the information needed for the task? } \\
\text { How difficult is it to locate and identify the math embedded in the materials? }\end{array}$ \\
\hline
\end{tabular}


numeracy-related practices and experiences, and literacy skills. While described individually below, these enabling processes work together as an adult tackles a numeracy task.

Context/world knowledge. In order to interpret mathematical information, individuals must have a sense for the context by accessing their world knowledge and personal experiences. For example, being able to think critically about statistical claims about data requires individuals to have the background knowledge and experience to make comparisons. One important and relevant context is the many statistical claims made during election years. Students need to understand what seems reasonable, even making the effort to learn more in order to judge the veracity of the claims.

\section{Mathematical knowledge and conceptual} understanding. PIAAC refers to conceptual understanding as an integrated and functional grasp of mathematical ideas (Conceptual Framework, p. 29). Terms such as meaning making and relationships are synonymous with conceptual understanding. Without conceptual understanding, adult learners will continue to have to memorize procedures over and over again. Conceptual understanding can help individuals make reasonable estimates and rely more on sense-making rather than rules and procedures. There is no quick way to teach for understanding. Students will need many opportunities to explore and to make connections among math ideas.

\section{Adaptive reasoning and problem-solving}

skills. Adults have a variety of strategies for solving problems - some learned through formal schooling and other developed informally or intuitively over time. Problem-solving strategies may include extracting relevant information from the task; rewriting or restating the task; drawing pictures, diagrams or sketches; guessing and checking; making a table; or generating a concrete model or representation (Conceptual Framework, p. 29). The more connections students are able to make among big math ideas, the more they will be able to adapt their reasoning; they will be able to use different strategies to work through situations.

Beliefs and attitudes. How an individual responds to a numeracy task depends on attitudes, beliefs, habits of mind, and prior experiences, not just knowledge and skill. The belief that one is not good with numbers, for example, affects how someone reacts to a task involving math. Such negative attitudes and beliefs about numeracy tasks are often exemplified in the adult education classroom. Productive disposition, the "habitual inclination to see mathematics as sensible, useful, and worthwhile, coupled with a belief in diligence and one's own efficacy" (National Research Council, 2001, p. 116), is key to being able to stick it out long enough to work through a situation involving numerate behavior. In reallife situations, adults with negative attitudes and beliefs about math often try to dodge the task and rely on others, thereby avoiding engagement in mathematical tasks. Addressing adult learners' attitudes about math to help them build a productive disposition is possibly the greatest challenge for teachers.

\section{Numeracy-related practices and experiences.}

Mathematical knowledge and skills develop through formal schooling and informally throughout life. The frequency with which individuals engage in mathematical tasks also influences numerate behavior. The more often adults engage in numeracy tasks and the more varied the tasks, the more likely their attitudes and beliefs will be affected. These processes are closely intertwined.

This notion of past practices and experiences can 
also be another challenging factor to address in adult education. Many adult learners have only been exposed to procedures, and that is what they believe math is: "fractions, decimals, percentages, algebra." Mathematical knowledge develops both in and out of school. If students are only exposed to procedures without context, chances are that they will not develop a strong mathematical understanding regarding when and where and how to use math in their lives. Adult students may need to have classroom experiences different from what they have had in the past; teachers may need to help students link 'school math' with the math they use in everyday life.

\section{Literacy skills. One form of mathematical} information is text - words rather than symbols or numerals; for example, "Seventy-five percent of the voters..." But, more than just words written in place of numerals, words within a mathematical context can be quite challenging. For example, fifty divided by vs. fifty divided into can stump students, especially if they have not had a great deal of experience with division to draw upon. If students have only been exposed

\section{Table 7: Enabling factors addressed in a simple task}

TASK: Survey the class on a question that you want to know more about, making sure to ask for yes/no responses only. Create a pie chart representation and explain using benchmark fractions and percents what the results were.

CONTEXT/WORLD KNOWLEDGE
For this task, most students will have
had some experience filling out a survey
(even a simple satisfaction survey for a
restaurant, etc.). An important element
of collecting and analyzing data is to
consider the validity of the data; at this
level, students can talk about whether
the data is representative of the entire
adult education program, the entire
state, etc.

\section{BELIEFS AND ATTITUDES}

Even though many adult learners feel that they are not good at math, participating in tasks such as creating and conducting a survey can feel like a new, 'non-school-math' activity, so there is a good chance that students will have a much more positive attitude about getting actively involved.
MATHEMATICAL KNOWLEDGE AND CONCEPTUAL UNDERSTANDING

Students are focusing on pie charts and percentages here, so they need to understand how to find the total and whether one set of responses (yes or no) is equivalent to half the total, or less than or more than the total. At this level, students are not asked to calculate exact percentages since the focus is on the benchmark $50 \%$.
ADAPTIVE REASONING AND PROBLEM-SOLVING SKILLS

With a small sample, students should be able to add the total number of responses, then figure out what half of the total is (so that they can figure how the two sets of responses compare to the total). For those students who struggle, they may draw a picture, use manipulatives, or even use a calculator to check their reasoning.

\section{NUMERACY-RELATED PRACTICES} AND EXPERIENCES

For those students who have experienced math as mostly procedural, there may be some hesitation in estimating with the size of the two slices of the pie graph using pie plates. Students who think math is only 'one right answer' may need lots of experience focusing first on estimation rather than immediately trying to find THE answer.

\section{LITERACY SKILLS}

For this task, students create their own question that they then ask their classmates. The teacher can help with spelling or wording, since the goal is to create a question that can be answered in a yes/no fashion, not whether someone can spell correctly. Students create their own charts and orally explain their results, so few literacy skills are needed here. 
to decontextualized division problems that have already been set up for them to compute, their exposure to the words that express the 'set-up' of the problem may be limited.

Let's look at the same task that we discussed with the facets of numeracy to see how the enabling processes can influence how students address the task or activity.

The following questions should guide the teacher as she considers the enabling factors that may help or inhibit her learners as they address the activity/ task she has designed for them.

\section{Table 8: Enabling processes of numerate behavior - questions to consider}

\section{ENABLING PROCESSES OF \\ NUMERATE BEHAVIOR \\ Context/world knowledge \\ Mathematical knowledge and conceptual understanding \\ Adaptive reasoning and problem-solving skills}

Beliefs and attitudes

Numeracy-related practices and experiences

Literacy skills

\section{QUESTIONS A TEACHER MIGHT ASK HERSELF}

What experiences and prior knowledge do students have related to the context? Is there something that we need to do in class to familiarize students with the context? Do students have the requisite understandings on which to build new understanding? Do students really understand the math or do they simply try to follow procedures?

Do students know how to self-monitor to see if they are on the right track?

Do students know how to begin to tackle the situation?

How comfortable are students with the math content to be addressed?

How comfortable are the students with the context?

What kinds of prior experiences have students had with the content?

How much number sense do students have regarding the content?

How much reading is required for the situation?

What is the level of text complexity?

How difficult is it to locate and identify the math embedded in the materials? How embedded is the math?

Is there writing involved? If not, is there a way that it might be included? 


\section{Proficiency as a Continuum}

In examining the facets of numerate behavior and the related enabling factors, it makes sense that the difficulty of a numeracy task is influenced by changes in both the enabling factors and the facets. Understanding how these influence the difficulty of a task can help teachers figure out how to adjust numeracy tasks based on the needs and abilities of their students. One of the key features of the PIAAC framework is that it is based on the belief that numeracy proficiency runs along a continuum. [This is a very different model from thinking of math as learning discrete sets of skills, such as fractions, decimals, geometry, etc.] The continuum, as used in the PIAAC assessment framework, is based on several criteria, described in PIAAC as factors that affect complexity:

- type of match/problem transparency

- plausibility of distractors

- complexity of mathematical information/data

- type of operation/skill

- expected number of operations

These five complexity factors are intended to take into account all facets of numerate behavior - the variety of contexts, mathematical ideas/content, responses, and representations. The first two aspects of complexity of a task relate to text how the information is presented. The last three aspects relate specifically to the math operations or activities that an adult has to engage with to accomplish the task; however, the five factors are interconnected. While these complexity factors were used in developing PIAAC assessment tasks, they can also be useful in developing meaningful yet differentiated tasks in the classroom.

Let's look at each of these complexity factors in more detail.
Type of match/problem transparency. This factor combines two factors related to how straightforward the problem is. Transparency describes the problem itself. It has to do with the explicitness of the information needed to solve a problem. At a lower level, there may be little or no text, and it is obvious what must be done with the information. At higher levels, there could be very dense text from which an adult must extract relevant mathematical information. The concept of type of match has to do with what an individual has to do with the text in order to find the information necessary to solve the problem. For example, a highly transparent problem might require a person to simply locate information in a text. A less transparent problem might require the person to search several pieces of information in order to extract the information necessary to address the task. A simple set of examples to illustrate this involves the task of comparing data.

Ex. 1: Based on the GED test data in 2001, the median score for test takers in math was 475. In 2003, it was 470 and in 2010 it was 469. What is the difference between the highest and lowest median score for those three years?

Ex. 2: Review the GED test data from 1999 - 2010 to determine which year test takers had the highest median score in math.

In the first example, the data are provided, but not in the second example. An individual would have to search through several years of reports to find the data needed for the situation.

Plausibility of distractors. Easy tasks would involve using text that has just the right amount of information. Many typical word problems that give just enough information would be considered simple. Moving toward the complex end of the spectrum would be tasks that include a lot of information that has to be read to find the relevant information and sometimes may not even include relevant information such as a formula needed to address the problem. 
Consider these two simple examples to illustrate the complexity factor related to distractors:

Ex 1: According to the bus schedule, John can catch it at 6:33 p.m. for a 7:45 p.m. arrival downtown. How long will his ride be?

Ex 2: Use the bus schedule to determine which bus to take to be sure to arrive downtown before 8:00 p.m.

In the first example, the information is straightforward; the beginning and ending times are given so the student does not have to look for the information. In the second example, the information is imbedded in the schedule. The times are not provided so the student has to use the bus schedule to locate the necessary information.

\section{Complexity of mathematical information/}

data. This complexity factor looks at the range from concrete to more abstract mathematical information, such as counting the number of items in each box vs. analyzing a complex graph or applying a detailed formula. Imagine two different bar graphs, both depicting the number of errors made per day. In the first graph, there are three simple bars, each representing only the total number of errors for the day. In the second graph, the number of errors is broken down by shift in a series of stacked bars.
Complexity also ranges from the familiar to the unfamiliar. The more familiar the context in which the mathematical information is presented, the easier the task. Tasks that are situated in an unfamiliar context can ratchet up the complexity level, even if the numbers themselves are not too challenging.

Students who have only been exposed to the typical bar graphs where each bar represents only one category will find this second graph challenging. The bars are more challenging to read, and the graph type itself may be unfamiliar.

Type of operation/skill. Clearly a mathematical situation involving addition and subtraction of whole numbers is much simpler than one requiring dividing fractions. An example of varying complexity based on type of operation or skill is determining simple vs. compound interest. The compound interest formula $[\mathrm{A}=\mathrm{P}(1+\mathrm{r} / \mathrm{n})$ $\left.{ }^{n t}\right]$ requires an understanding of exponents and the graph of the situation is exponential. Even though this might be the most obvious way to vary difficulty, it is important to vary the difficulty of a task by considering other complexity factors as well.
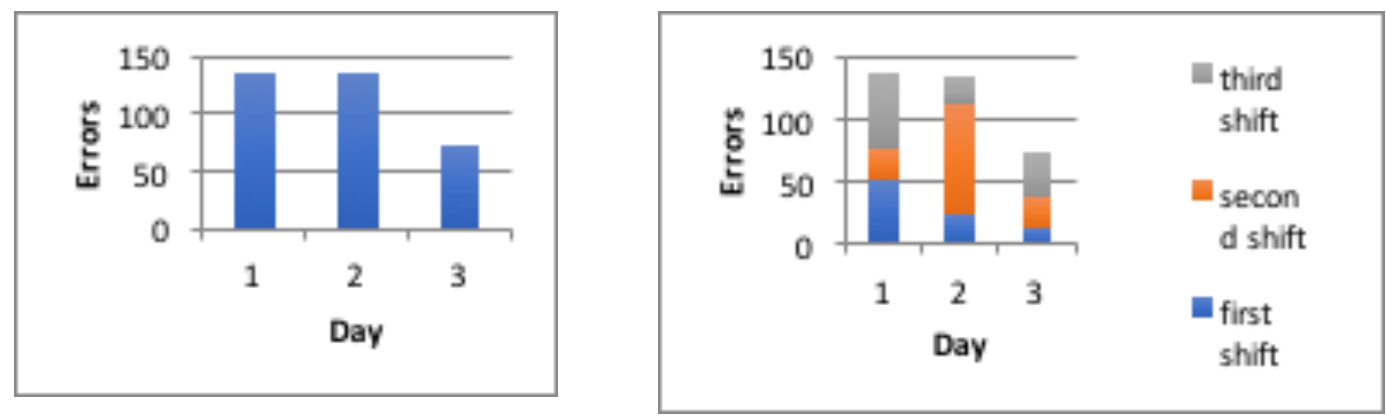
Expected number of operations. Tasks that involve one step are considered less complex than those involving more than one step. We all have seen students who stop working on a problem after they have completed the first of a series of steps. It seems that the more steps there are, the more likely students are to get lost in the process. Here are two simple examples to show the difference in complexity.

Ex. 1: A coat that regularly costs $\$ 456$ is on sale for $25 \%$ off. How much would you save by buying it at the sale price?

Ex. 2: A coat that regularly costs $\$ 456$ is on sale for $25 \%$ off. What is the sale price?

In the first example, an individual only needs to calculate the amount saved. In the second example, there could be a second step required to figure out the new price once the amount saved based on sale is determined. Or, an individual could first determine the percent of the regular price $(100 \%$ - 25\%), then determine the new price. But, in either case, the second example requires two steps.

Understanding how to change a task to make it more challenging or more accessible will help teachers develop activities that are meaningful to all learners, yet move them all along the continuum from novice to expert. It does take time, but with practice, teachers can develop a sense of how to efficiently adjust tasks for her students.

\section{SIMPLE TASKS}

- explicit information

- no distractors

- concrete information (actual or visual)

- whole numbers and benchmark fractions, decimals, percents

- one operation $(+,-, x, \div)$
MOVING ALONG THE CONTINUUM

- information becomes less obvious

- distractors begin to appear in the information

- mathematical ideas and content become more challenging

- multi-steps are needed to address the situation

\section{COMPLEX TASKS}

- information hidden, challenging to sort through

- lots of distractors

- abstract information or presentation of material

- complex mathematical information

- multiple operations 
The following questions should guide the teacher as she considers how to tweak a task to address the various needs of her learners.

\section{Table 9: Complexity factors - questions to consider}

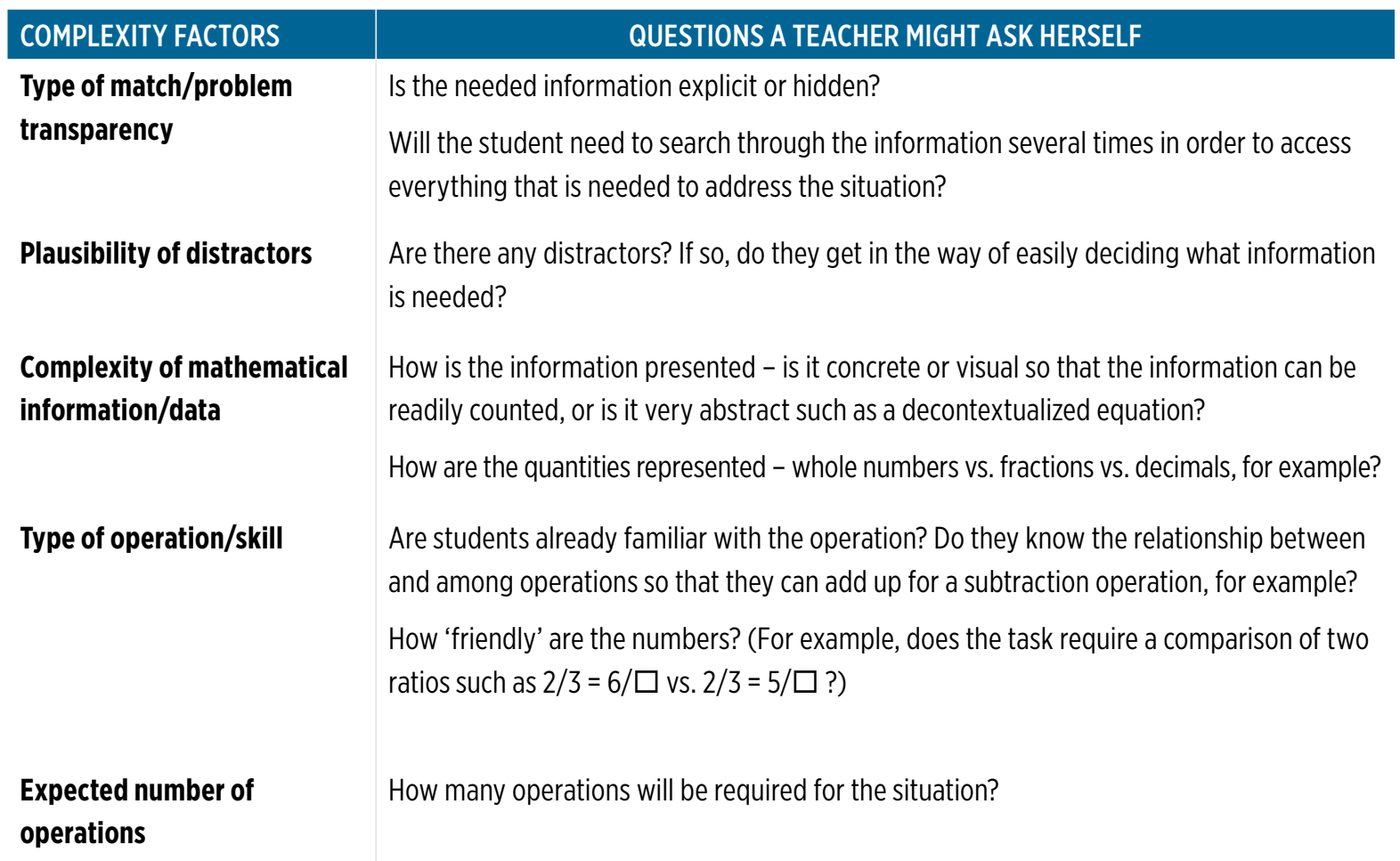




\section{Putting It All Together}

Let's revisit the four examples of analyzing nutritional labels at the beginning of this article. We should now be able to better articulate what factors made each of the tasks easier or more challenging, providing several tasks so that students at various levels could all participate in classroom discussions about nutrition, but then tackle a task that was appropriate for their particular needs.

\section{Table 10: Similar but different tasks - analyzed}

TASK 1: Amy can only eat $10 \mathrm{~g}$. of sugar per day. If she eats one serving of this cereal, how many more grams of sugar can she have during the rest of the day?

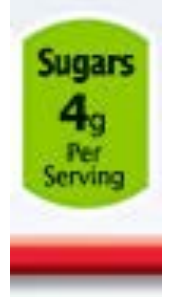

The original label had lots of information. It was removed so that the necessary information was readily available for the student; in other words, there are no distractors. This task requires only one operation - subtraction (or adding up from 4 to 10), so overall this is a low-level task.

TASK 3: Amy's doctor has told her that she needs to reduce her calorie intake down to 1500 per day. If she eats a serving of this cereal, explain what percent of her daily calorie intake she has consumed.

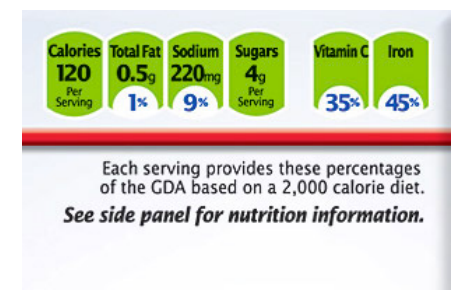

This has been made into a very challenging problem because the calorie intake was reduced by $25 \%$, making calculations more complex. The students have to read the label carefully to understand that the data are based on 2,000-calorie diet, not 1,500. This ratchets up the level of the task.
TASK 2: Compare the nutritional information of the cereal below with the cereal you usually buy. Create a chart showing how the two compare, then be prepared to explain which cereal is the healthier choice for your specific needs.

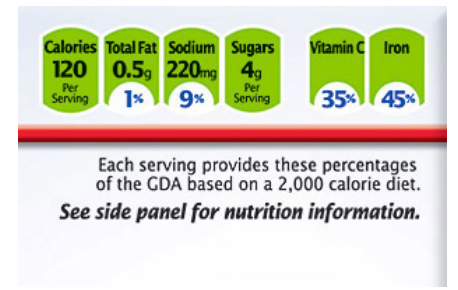

This task requires that a student go find other nutritional information to compare with what is given; this in itself makes the task more challenging. The student will have to compare much of the nutritional information in order to make a decision that she can then reasonably justify, so the task requires more than just finding an comparing nutritional information. This is higher level task.

TASK 4: Amy can only eat $10 \mathrm{~g}$. of sugar per day. If she eats one serving of this cereal, how many more grams of sugar can she have during the rest of the day?

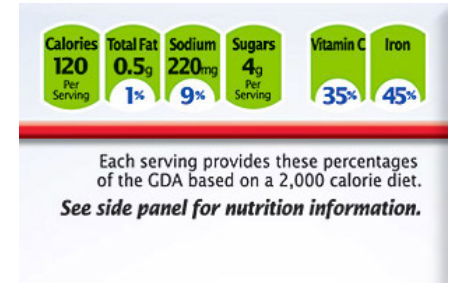

This task is exactly the same as the first example. What makes this just a little more challenging is that there are distractors - other nutritional information that could get in the way of the student figuring out exactly what information is needed for the situation. This is a fairly low level task based on the math required, but higher than the first task since there is additional information imbedded in the task. 
So far, we have discussed several key elements of the PIAAC assessment framework, including facets of numerate behavior, enabling processes that support such behavior, and complexity factors that determine the difficulty of the task requiring numerate behavior. While we have discussed these in isolation, they are all integrated and interdependent.

Let's look at how they can influence each other with a couple of specific examples.

\section{Table 11: Decontextualized problems vs. real-life tasks}

A typical decontextualized fraction problem: $1 / 2(1-1 / 3)=x$

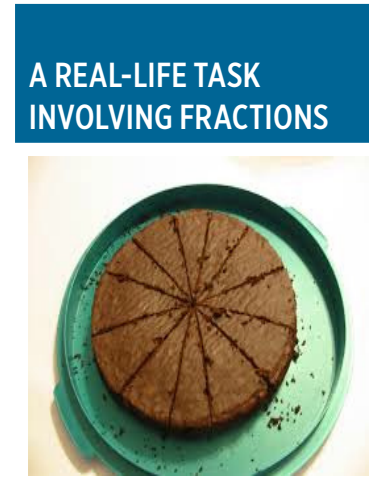

You work the late shift at Getz Bakery and need to prepare a report of what is sold at the end of each day. On Monday $1 / 3$ of the slices of cake were sold. On Tuesday, $1 / 2$ of what was left was sold. What portion of the original cake would you report was sold on Tuesday?

\section{FACETS OF \\ NUMERATE \\ BEHAVIOR}

Context: could be

work or adults'

personal lives

Responses: act

upon

Mathematical content/ information/ ideas: number sense -

fractions

Representations

of mathematical

information:

includes text and a

picture

\section{ENABLING PROCESSES TO SUPPORT} NUMERATE BEHAVIOR

Mathematical knowledge and conceptual understanding: requires an understanding of what happens when a fraction of a fraction is taken

Adaptive reasoning and problemsolving: students might choose a variety of strategies as they work through the situation. Many may try different operations (adding, subtracting, multiplying, dividing) but should be able to reason whether the result makes sense; drawing a picture to visual this situation could be beneficial to make sense of the situation

Literacy skills: some skill needed, although fractions are in symbols and numbers

Context/world knowledge: most students probably know that cakes are sliced into equal parts

Beliefs and attitudes: for adult learners to succeed with this task, they need to believe that they can work with fractions

Numeracy-related practices and experiences: learners will tend to perform some operation, possibly depending on their memory of fraction procedures
COMPLEXITY FACTORS

THAT DETERMINE THE DIFFICULTY OF THE TASK

Problem transparency: mathematical information is obvious

Plausibility of distractors: none

Complexity of mathematical information/ data: somewhat abstract but object is familiar Type of operation/skill: challenging for most adult learners because it involves multiplying fractions Number of operations: requires more than one operation 


\title{
Table 11: Decontextualized problems vs. real-life tasks (continued from previous page)
}

\author{
A typical decontextualized algebra problem: $x+20=4 x$
}

\begin{tabular}{|c|c|c|c|}
\hline $\begin{array}{l}\text { A REAL-LIFE TASK THAT } \\
\text { INVOLVES ALGEBRAIC } \\
\text { REASONING }\end{array}$ & $\begin{array}{l}\text { FACETS OF } \\
\text { NUMERATE } \\
\text { BEHAVIOR }\end{array}$ & $\begin{array}{l}\text { ENABLING PROCESSES TO SUPPORT } \\
\text { NUMERATE BEHAVIOR }\end{array}$ & $\begin{array}{l}\text { COMPLEXITY FACTORS } \\
\text { THAT DETERMINE THE } \\
\text { DIFFICULTY OF THE TASK }\end{array}$ \\
\hline $\begin{array}{l}\text { Lavonne’s granddaughter } \\
\text { wants to go to the } \\
\text { community fair. There } \\
\text { are two prices for tickets: } \\
\text { either an individual pays } \\
\$ 20 \text { entrance fee and } \\
\text { then pays only } \$ 1 \text { per ride, } \\
\text { or the individual pays } \\
\text { no entrance fee but has } \\
\text { to pay } \$ 4 \text { per ride. How } \\
\text { can Lavone explain in a } \\
\text { graph and an equation } \\
\text { the options based on } \\
\text { the number of rides her } \\
\text { granddaughter thinks she } \\
\text { might want to go on? }\end{array}$ & $\begin{array}{l}\text { Context: adults' } \\
\text { personal lives } \\
\text { Responses: } \\
\text { interpret, } \\
\text { evaluate, analyze, } \\
\text { communicate } \\
\text { Mathematical } \\
\text { content/ } \\
\text { information/ } \\
\text { ideas: Patterns, } \\
\text { relationships and } \\
\text { change } \\
\text { Representations } \\
\text { of mathematical } \\
\text { information: } \\
\text { needed information } \\
\text { is presented in } \\
\text { text; but individual } \\
\text { will represent the } \\
\text { solution graphically } \\
\text { and symbolically }\end{array}$ & $\begin{array}{l}\text { Mathematical knowledge and conceptual } \\
\text { understanding: requires an understanding } \\
\text { of variables and operations } \\
\text { Adaptive reasoning and problem-solving: } \\
\text { Students could use concrete manipulatives } \\
\text { to support their reasoning } \\
\text { Literacy skills: some skill needed, especially } \\
\text { understanding terms such as 'per' } \\
\text { Context/world knowledge: understanding } \\
\text { that there are situations in which you pay } \\
\text { up front to enter an environment even if } \\
\text { you don't participate in activities } \\
\text { Beliefs and attitudes: because this situation } \\
\text { is grounded in a real-life experience, } \\
\text { students are more likely to try to work } \\
\text { through the problem than they would if } \\
\text { they only had the original problem; many } \\
\text { students fear algebra } \\
\text { Numeracy-related practices and experiences: } \\
\text { depending on adult learners' experiences, } \\
\text { they may initially tackle this situation by } \\
\text { creating two tables to compare the two } \\
\text { options as the number of rides increases }\end{array}$ & $\begin{array}{l}\text { Problem transparency: } \\
\text { mathematical information } \\
\text { is obvious but it needs to be } \\
\text { separated into two different } \\
\text { options } \\
\text { Plausibility of distractors: } \\
\text { none } \\
\text { Complexity of mathematical } \\
\text { information/ data: money } \\
\text { is familiar to students and } \\
\text { amounts are in whole } \\
\text { numbers } \\
\text { Type of operation/skill: } \\
\text { what makes this task } \\
\text { more challenging is that } \\
\text { students are asked to create } \\
\text { equations; if they only had to } \\
\text { use a table of other strategy, } \\
\text { this would have been } \\
\text { considered an easier task } \\
\text { Number of operations: } \\
\text { more than one operation } \\
\text { and a comparison of two } \\
\text { situations }\end{array}$ \\
\hline
\end{tabular}

While there are several components to the PIAAC assessment framework, in this article we have focused mainly on the critical component of numeracy as use-oriented and numeracy along a continuum. The definitions of numeracy and numerate behavior illustrate the concept of 'useoriented'. Teachers adopting PIAAC's use-oriented definition of numeracy are more likely to realize that teaching discrete, decontextualized skills is not benefiting their students. Students need to be able to apply their skills in increasingly challenging situations in order to effectively manage their lives, whether it is at work, home, in further schooling, or in the community. Teachers who understand the PIAAC numeracy framework components will be able to adjust instruction to ensure that all their students are challenged to continue to move along the continuum of what it means to be numerate. 


\section{References}

Givvin, K.B, Stigler, J.W., \& Thompson, B.J. (2011). What community college developmental mathematics students understand about mathematics, part 2: The interviews. MathAMATYC Educator, 2(3), 4-18.

National Research Council. (2001). Adding it up: Helping children learn mathematics. Washington, D. C.: National Academy Press.

Organisation for Economic Co-operation and Development (OECD) (2013a). The Survey of Adult Skills: Reader's Companion. Paris, France: OECD Publishing. doi:10.1787/9789264204027-en
Organisation for Economic Co-operation and Development (OECD). (2013b). The OECD skills outlook 2013: First results from the Survey of Adult Skills. Paris, France: OECD Publishing.

OECD. (2012). PIAAC Conceptual Framework of the Background Questionnaire Main Survey. (2011). Paris, France: OECD Publishing.

PIAAC Numeracy Expert Group. (2009). PIAAC Numeracy: A conceptual framework. Paris: OECD. http://www.oecd.org/edu/oecdprogrammeforthein ternationalassessmentofadultcompetenciespiaacdocumentation.htm 